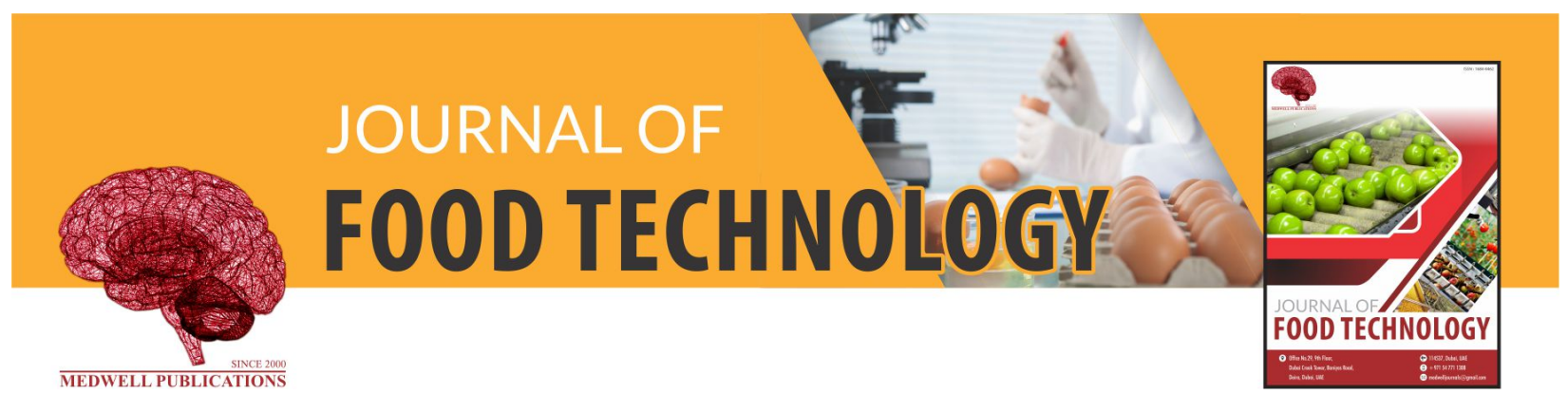

\title{
Engineering of Some Physico-Chemical Properties of Amorphous Spray-Dried Inulin using a Response-Surface Design
}

\author{
${ }^{1}$ Brahim Bchir, ${ }^{2}$ Sebastien N. Ronkart, ${ }^{3}$ Yves Brostaux, ${ }^{2}$ Lynn Doran, ${ }^{4}$ Christian Fougnies and ${ }^{2}$ Christophe \\ Blecker \\ ${ }^{1}$ Nutritional Analysis Lab, Departmentof Biology, School of Engineers of Sfax, University of Sfax/National, \\ Rod. Soukra Drive, 3038 Sfax, Tunisia \\ ${ }^{2}$ Department of Food Science and Formulation, University of Liege, Gembloux Agro-Bio Tech Passage des \\ Deportes, B-5030 Gembloux, Belgium \\ ${ }^{3}$ TERRA Research and Teaching Center-Forest Is Life Gembloux Agro-Bio Tech, \\ ${ }^{4}$ University of Liege, Passage des Deportes, B-5030 Gembloux, Belgium Cosucra Groupe Warcoing S.A., Rue \\ de la Sucrerie, 1, B-7740, Warcoing, Belgium
}

Key words: Inulin, spray-drying, powder, physicochemical properties, surface response, statistical

\section{Corresponding Author:}

Brahim Bchir

Nutritional Analysis Lab, Departmentof Biology, School of Engineers of Sfax, University of Sfax/National, Rod. Soukra Drive, 3038 Sfax Tunisia

Page No.: 24-32

Volume: 17, Issue 2, 2019

ISSN: $1684-8462$

Journal of Food Technology

Copy Right: Medwell Publications
Abstract: The aim of this study was to investigate the effect of some process variables on the physico-chemical properties of amorphous inulin. In this context, a three-factor second-order response-surface model was fitted to five variables. The factors were feed concentration and temperature and inlet air temperature while the five variables were bulk and tapped density, particles size, moisture content and the glass transition temperature. In the feed concentration $(10-40 \%, \mathrm{w} / \mathrm{w})$, feed temperature $\left(40-90^{\circ} \mathrm{C}\right)$ and inlet air temperature $\left(120-230^{\circ} \mathrm{C}\right)$ range tested, statistical analysis revealed that physico-chemical properties of inulin were mainly governed by inlet air temperature and the feed concentration to a lesser extent. The feed temperature was secondary in comparison with the two first factors. In regards to the production parameters, a qualitative microscopic study allowed to visualize the morphological property changes and to correlate them to the physicochemical properties.

\section{INTRODUCTION}

Spray-drying is an important technique in the food industry for producing ingredients in a powder form. It produces particles by atomizing a suspension or a solution (named feed) and evaporating moisture from the resulting droplets by suspending them in a hot gas. While moving in this hot medium, the droplets are dried into powder particles (Alamilla-Beltran et al., 2005; Samborska et al., 2018; Chen et al., 2019). In the industry, spray-drying is widely used for its high dehydration capacity (up to several tons/hour) but also has the advantage of low production costs compared to other drying techniques (e.g., freeze-drying) (Ahmed et al., 2018).

The aim of spray-drying is not only a dehydration technique but also plays a important role in the engineering of the physico-chemical properties of the powder like density, particles size, moisture content, crystallinity, etc. (Birchal et al., 2005; Vega et al., 2018). Although, the impact of spray-drying on some of the 
powder's properties has been well known for more than half a century, industrial scale studies are very few in the literature. One of the main reasons is probably for confidential reasons but also because spray-drying trials remain very complicated and expensive under industrial conditions as they need big quantities of products. Although, pilot spray-driers are not able to produce powders with identical bulk properties as those generated on an industrial scale, they are interesting tools for investigating the feed and the drying parameters on the physico-chemical properties of the powder (Nath and Satpathy, 1998; Haraguchi, 2015; Chen et al., 2019). In a previous study, Ronkart et al. (2006) and Ahmed et al. (2018) showed that the feed and inlet air temperatures of the spray-drier had an impact on the amorphous/crystallinity content of the inulin powder, a polymer of fructose. The solid amorphous is out of equilibrium with respect to the crystalline form and thus phase transformations can occur within the shelf-life of the powder (Ronkart et al., 2009 a, b; Jirayucharoensak et al., 2019). However, it is of interest to produce solid amorphous powders as they are likely to show increased solubility and dissolution rates when compared to their crystalline counterparts (Hancock and Parks, 2000). Because of unique properties such as open and porous structure, high surface energy or high ability to interact with external molecules, amorphous powders have received a lot of attention for food applications (Bchir et al., 2019).

For this reason, the aim of this study was to evaluate the effects of process (spray-drying) and formulation (feed) parameters on some pertinent physico-chemical properties of amorphous inulin. In this study, a fractional factorial design was built to estimate the influence of both the different factors (feed temperature, feed concentration and inlet air temperature of the spray-drier) and their interactions on five responses (bulk and tapped density, particles size, moisture content and glass transition temperature). In addition, selected powders were analyzed by electron microscopy to determine the relationship between morphological structure and some of their properties such as bulk density or particle size.

Practical applications: Spray drying is considered one of the most economic drying techniques, due to its low operational expenditures. However, it inevitably causes modification of the powder characteristic such as crystallinity, morphology, size, etc. The degree of quality modification of spray-dried samples varies depending on materials and essentially on spray drying condition (e.g., feed temperature, feed concentration and inlet air temperature of the spray-drier). The study of the influence of spray drying condition on the characteristic of inulin in terms of water distribution, structural changes, bulk and tapped density, particles size and glass transition temperature is of importance to better control the quality of inulin production in the industry.

\section{MATERIALS AND METHODS}

The inulin used in this study was a commercial spray-dried native inulin extracted from chicory roots kindly supplied by Cosucra Groupe Warcoing SA (Warcoing, Belgium). It is composed of fructose unit chains (linked by $\beta-(2 \rightarrow 1)$-D-fructosyl-fructose bonds) of various length, terminated generally by a single glucose unit (linked by an $\alpha$-D-glucopyranosoyl bond). A High Performance Anion Exchange Chromatography coupled with Pulse Amperometric Detection (HPAEC-PAD) was used to determine the molecular mass distribution. The chromatographic system (Dionex DX500) was operated at $1 \mathrm{~mL} / \mathrm{min}$. About $25 \mu \mathrm{L}$ of a $0.8 \mathrm{~g} \mathrm{~L}^{-1}$ solution were injected. As described by Ronkart et al. (2006), Dionex PA100 column was used to separate the various chain lengths. Inulin had an average degree of polymerisation number and weight of 6.4 and 13.4, respectively.

Preparation of spray-dried inulin: Preliminary experiments were carried out to establish appropriate ranges for the processing variables in order to obtain amorphous inulin powders. Lower feed temperature and/or higher feed concentration than those selected in this study led to the crystallization of inulin before the spray-drying while the inlet air temperature range was compatible with those encountered in the industry.

Inulin was dispersed in distilled water to a solid concentration of 10,25 and $40 \%(\mathrm{w} / \mathrm{w})$ at different temperatures $\left(40,65\right.$ and $\left.90^{\circ} \mathrm{C}\right)$. The inulin dispersions were spray-dried in a pilot plant scale Anhydro Lab S1 spray-drier (Anhydro, Denmark). The liquid was dispersed into a mist in a two fluid nozzle by means of compressed air. The nozzle was puted in the middle of the drying chamber spraying upwards while the hot air was simultaneously introduced through an annular opening in the drying chamber ceiling. During the experiments, the liquid feed flow and the nozzle air flow pressure were $2 \mathrm{l} / \mathrm{h}$ and 2 bars, respectively. The inlet air temperatures were 120,175 and $230^{\circ} \mathrm{C}$ and corresponded to an outlet air temperature of 66-69, 95-99 and $120-125^{\circ} \mathrm{C}$, respectively whatever the feed concentration and temperature.

The selected feed and drying parameters were selected, so that, completely amorphous inulin was obtained. Indeed, wide angle X-RAY scattering diffracto grams in the $4^{\circ}<2 \mathrm{q}<30^{\circ}$ range (data not shown) exhibited broad and diffuse maxima with no diffraction peak which is characteristic of amorphous inulin (Ronkart et al., 2006).

Experimental design: In order to limit the number of experiments, a fractional factorial design $\left(3^{3-1}\right)$ was generated using defining contrast. It permitted to evaluate 
Table 1: Design matrix of the fractional factorial design. $\mathrm{x}_{1}-\mathrm{x}_{3}$ are the coded factors and correspond to the feed concentration, feed temperature and inlet air temperature, respectively

\begin{tabular}{lrr}
\hline $\mathrm{X}_{1}{ }^{\mathrm{a}}$ & $\mathrm{X}_{2}{ }^{\mathrm{b}}$ & $\mathrm{X}_{3}{ }^{\mathrm{c}}$ \\
\hline$-1(10)$ & $-1(40)$ & $-1(120)$ \\
$+1(40)$ & $-1(40)$ & $0(175)$ \\
$0(25)$ & $-1(40)$ & $+1(230)$ \\
$0(25)$ & $0(65)$ & $-1(120)$ \\
$-1(10)$ & $0(65)$ & $0(175)$ \\
$+1(40)$ & $0(65)$ & $+1(230)$ \\
$+1(40)$ & $+1(90)$ & $-1(120)$ \\
$0(25)$ & $+1(90)$ & $0(175)$ \\
$-1(10)$ & $+1(90)$ & $+1(230)$ \\
\hline${ }^{\mathrm{a}} \mathrm{The}$ feed concentration is represented in parentheses and is expressed \\
in $\%(\mathrm{w} / \mathrm{w}),{ }^{\mathrm{b}}{ }^{\mathrm{T}} \mathrm{The}$ feed temperature is represented in parentheses and is \\
expressed in ${ }^{\circ} \mathrm{C}{ }^{\mathrm{c}} \mathrm{The}$ inlet air temperature is represented in parentheses \\
and is expressed in ${ }^{\circ} \mathrm{C}$
\end{tabular}

the effects of feed concentration and temperature and inlet air temperature on moisture content, bulk and tapped density, particles size and glass transition temperature of the powder. Each experimental condition was randomly realized in triplicate. It allowed the evaluation of the effect of the three factors at three levels with nine setting conditions (Table 1).

The experimental design was generated using the Fractional Design Wizard Software. Statistical analyses were performed using the R Software (v.2.8.1) and the rsm Package (v.1.10.).

\section{Powder characterization}

Bulk and tapped density: Densities were performed by filling with powder a graduated cylinder of $50 \mathrm{~mL}$. The bulk density was calculated as the ratio of the mass of the powder to the volume of the cylinder (precisely determined by distilled water). The tapped density was determined after 100 taps of the cylinder as the ratio of the height of the cylinder to the height of the packed powder, multiplied by the bulk density. Each powder was analyzed in triplicate with three different cylinders.

Particles size: The particles size distribution of the different samples was estimated with a LASER granulometer Mastersizer 2000 (Malvern Instrument, Malvern, UK) connected to a Scirocco 2000 device (Malvern Instruments) for dry measurements. A sufficient amount of powder was placed on a vibrating tray. Setting parameters (tray vibration and pressure) were controlled to obtain an obscuration value comprised between 10 and $20 \%$. The refractive index used was 1.53 . Measurements were performed at room temperature at least in duplicate. The average particle size, expressed in $\mu \mathrm{m}$, refers to the median diameter in volume (Bchir et al., 2019).

Moisture content: The moisture content was determined by weight loss by oven drying. A sample of around $5 \mathrm{~g}$ was heated at $105^{\circ} \mathrm{C}$ for $24 \mathrm{~h}$. The weight change caused by moisture loss was expressed in percent $(\mathrm{w} / \mathrm{w})$.
Glass transition temperature: The glass transition temperature was determined with a DSC 2920 TA Instruments (New Castle, Delaware, USA) with a refrigerated cooling assessory and modulated capability (Ronkart et al., 2006). Modulated Differential Scanning Calorimetry (MDSC) thermograms were obtained over a temperature range of $-50-200^{\circ} \mathrm{C}$ with a heating rate of $1.5^{\circ} \mathrm{C} / \mathrm{min}$ while the period and the amplitude of the MDSC were $90 \mathrm{sec}$ and $1.5^{\circ} \mathrm{C}$, respectively. All measurements were made at least in triplicate using hermetic aluminum pans.

Particle morphology: The particle shape and the surface morphology were investigated with an Environmental Scanning Electron Microscope (ESEM), XL30 type ESEM-FEG (Philips/FEI) at $20 \mathrm{kV}$ and a working distance of $10.0 \mathrm{~mm}$. The detection system used was a gaseous secondary electron detector.

\section{RESULTS AND DISCUSSION}

Response-surface design: Each variable (moisture content, particles size, bulk and tapped density and glass transition temperature) was fitted to a second-order saturated response-surface model. It contained the linear and quadratic terms associated to each factor (inlet air temperature and feed concentration and temperature) as well as the interactions between the feed concentration and feed temperature and between feed temperature and inlet air temperature. During the estimations, these models were adjusted on coded factors $(-1,0,+1)$. These values $-1,0$ and +1 are associated to low, medium and high values of the factors, respectively. These models were then simplified through a regressive selection process. For each stage (starting by the interactions, then the quadratic terms and finally the linear ones), non-significant terms were rejected from the model. Finally, the quality of adjustment of the final model was evaluated by a lack of fit test based on a pure error.

Moisture content: The selected model (Table 2) only included the linear and quadratic terms corresponding to the feed concentration $\left(\mathrm{x}_{1}\right) \mathrm{s}$ and feed temperature $\left(\mathrm{x}_{2}\right)$. It presented a residual error of 0.4477 (22 degrees of freedom, df) corresponding to the variable error which is not explained by the adjusted model. It also showed an adjusted- $\mathrm{R}^{2}$ of 0.909 corresponding to the proportion of the initial variance of the observations which is explained by the adjusted model. This model did not show any significant lack of fit $\left(\mathrm{F}_{4,18}=0.661, \mathrm{p}=0.627\right)$.

In our study, moisture content is negatively affected by the inlet air temperature and the feed concentration and did not depend on the feed temperature (Table 2 and Fig. 1a). An increase in inlet air temperature led to a decrease in moisture content, due to an enhanced water evaporation. These results are similar to those by Ahmed et al. $(2018,2019)$ who pointed out that the greater the temperature difference between the drying 

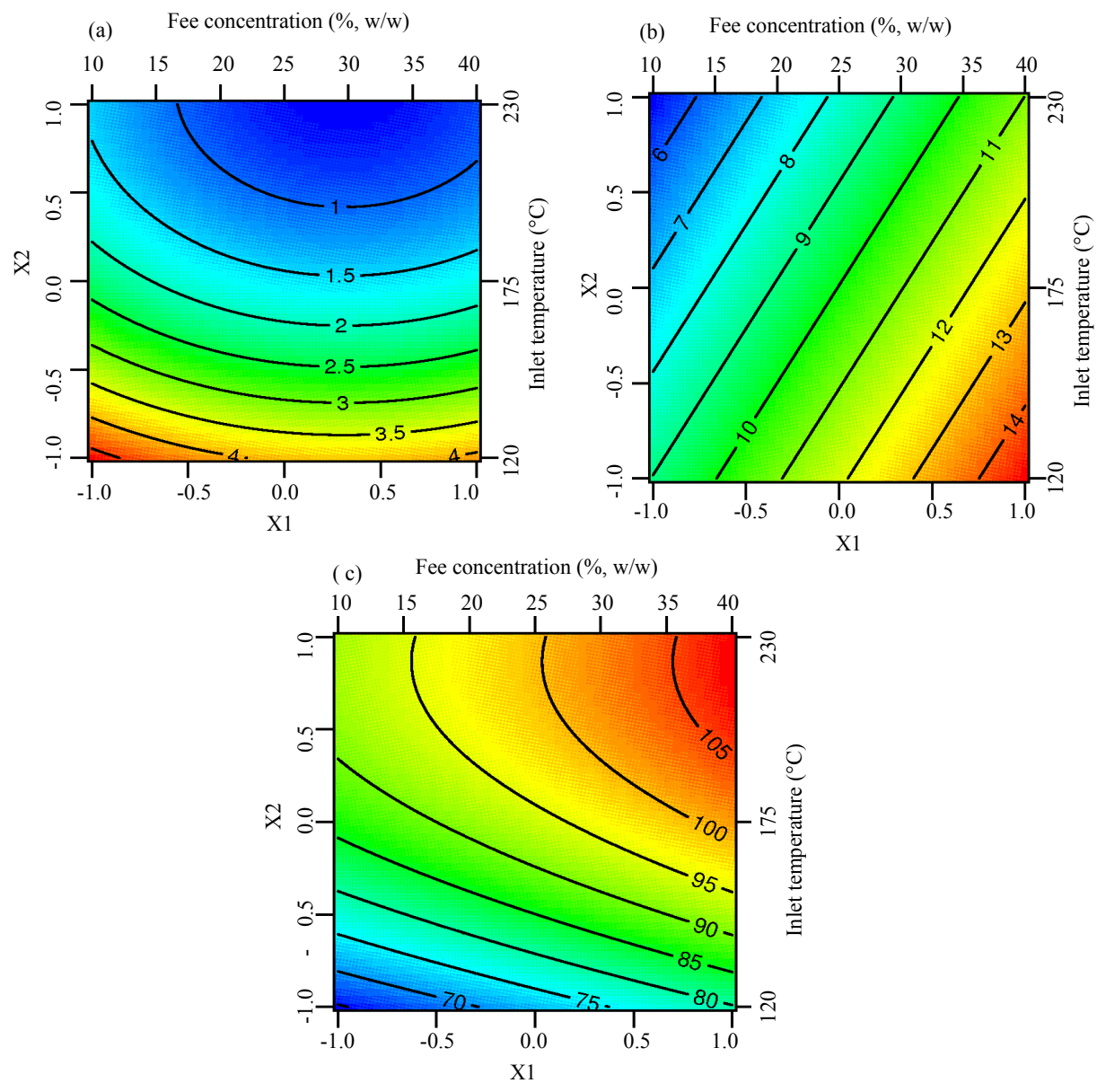

Fig. 1(a-c): Contour plot of the response-surface model fitted to moisture content (a) and particles size, (b) glass transition temperature and (c) $\mathrm{x}_{1}$ : feed concentration $(-1: 10 \%, 0: 25 \%,+1: 40 \%), \mathrm{x}_{2}$ : inlet air temperature $\left(-1: 120^{\circ} \mathrm{C}, 0: 175^{\circ} \mathrm{C},+1: 230^{\circ} \mathrm{C}\right)$

Table 2: Response-surface coefficients of the final fitted model for moisture content

\begin{tabular}{|c|c|c|c|c|}
\hline Variables & Coefficient & ${ }^{a} \mathrm{SE}$ & t-test & p-values \\
\hline Intercept & 1.5911 & 0.1926 & 8.260 & $<0.001 * * *$ \\
\hline $\mathrm{x}_{1}$ & -0.2811 & 0.1055 & -2.664 & $0.014^{*}$ \\
\hline $\mathrm{x}_{2}$ & -1.6117 & 0.1055 & -15.275 & $<0.001^{* * *}$ \\
\hline $\mathrm{x}_{12}$ & 0.4500 & 0.1828 & 2.462 & $0.022^{*}$ \\
\hline$x_{22}$ & 0.7250 & 0.1828 & 3.967 & $0.001 * * *$ \\
\hline
\end{tabular}

Table 3: Response-surface coefficients of the final fitted model for $\begin{array}{r}\text { particles size } \\ \hline\end{array}$

\begin{tabular}{|c|c|c|c|c|}
\hline Variables & Coefficient & SE & $\mathrm{t}$-test & p-values \\
\hline Intercept & 10.0237 & 0.2767 & 36.232 & $<0.001 * * *$ \\
\hline $\mathrm{x}_{1}$ & 2.8339 & 0.3388 & 8.364 & $<0.001 * * *$ \\
\hline$\underline{x}_{2}$ & -1.8433 & 0.3388 & -5.440 & $<0.001 * * *$ \\
\hline
\end{tabular}

medium and the particles, the higher the rate of heat transfer into the particles which provides the driving force for moisture removal. Consequently, powders with reduced moisture content are formed. To a lesser extent, the feed concentration positivelyaffected the moisture content. These results are consistent with others findings (Pinto et al., 2017; Jirayucharoensak et al., 2019). An increase in the concentration of the feed prior to spray-drying increased the total solid content and reduced the amount of water for evaporation, meaning a decrease of the moisture content of the powder. A higher feed concentration induced a better drying process which meant that powders with lower moisture content could be produced. However, if the percentage of inulin exceeded the upper level used in this study $(40 \%$, w/w), a crystallization occurred. Such a situation will lead to crystalline powders and a change of their properties in comparison with the amorphous ones but this is not the topic of the present paper.

Particles size: The selected model (Table 3) only had linear terms corresponding to the feed concentration and the inlet air temperature. It presented a residual error of 
Fig. 2(a-d): Electron microscopy photos of powder inulins illustrating the variation in particle morphology when produced from different spray-drying conditions, (a) ${ }^{\mathrm{a}} \mathrm{T}_{\text {in }}: 120^{\circ} \mathrm{C},{ }^{b} \mathrm{~T}_{\text {feed }}: 40^{\circ} \mathrm{C}$, (b) ${ }^{\mathrm{a}} \mathrm{T}_{\text {in }}: 230^{\circ} \mathrm{C},{ }^{b} \mathrm{~T}_{\text {feed }}: 40^{\circ} \mathrm{C}$, (c) ${ }^{\mathrm{a}} \mathrm{T}_{\text {in }}: 120^{\circ} \mathrm{C},{ }^{b} \mathrm{~T}_{\text {feed }}: 90^{\circ} \mathrm{C}$ and (d) ${ }^{\mathrm{a}} \mathrm{T}_{\text {in }}: 230^{\circ} \mathrm{C},{ }^{b} \mathrm{~T}_{\text {feed }}: 90^{\circ} \mathrm{C}$. The feed concentration was set at $40 \%(\mathrm{w} / \mathrm{w})$. The arrows represent some blow-out particles ${ }^{\mathrm{a} i n l e t}$ air temperature ${ }^{\mathrm{b}}$ feed temperature

1.4375 (24 df) and an adjusted- $\mathrm{R}^{2}$ of 0.790 . This model did not show any significant lack of fit $\left(\mathrm{F}_{6,18}=\right.$ $0.215, \mathrm{p}=0.967)$.

Inlet air temperature and feed concentration had negative and positive effects on the particles size, respectively and did not depend on the feed temperature (Fig. 1b). We observed that both the feed concentration and the inlet air temperature had a linear proportional impact on the particles size in similar rates and independently one of another. The negative impact of the inlet air temperature on the particles size is in opposition with the results by Ahmed et al. (2018). These researchers suggested that the increase in particle size might be an effect of increased agglomeration at the higher inlet air temperature. However, we did not observe agglomeration of inulin at any inlet air temperature used in this study (Fig. 2). It is interesting to visualize on the electron microscopy photos that inulin particles became more shrivelled in appearance as the drying temperature is reduced. Such observations have been previously reported by Alamilla-Beltra et al. (2005) on maltodextrin for which morphological differences may arise from differences in the rate of drying and physical characteristics of the crust (skin) which may be regarded as soft (at low inlet air temperature) or rigid (at high inlet air temperature). Based on the work by Nijdam and Langrish (2005) and Zhang et al. (2019) have attributed this phenomenon to the skin-forming characteristic of the particle during drying. At $\mathrm{T}_{\text {in }}=230^{\circ} \mathrm{C}$, a blow-out of the particles was observed as also reported by Toneli on chicory root inulin produced with a laboratory spray-drier with an inlet air temperature of $210^{\circ} \mathrm{C}$. This was probably due to an overpressure inside the particle due to an inner moisture gradient of the powder particles which lead to the rupture of the skin (Verdurmen et al., 2004; Ahmed et al., 2018). However, when the drying temperature is lower $\left(\mathrm{T}_{\mathrm{in}}=120^{\circ} \mathrm{C}\right)$, the outer surface remains moist and supple for longer, since, water diffusion is slow, allowing more 


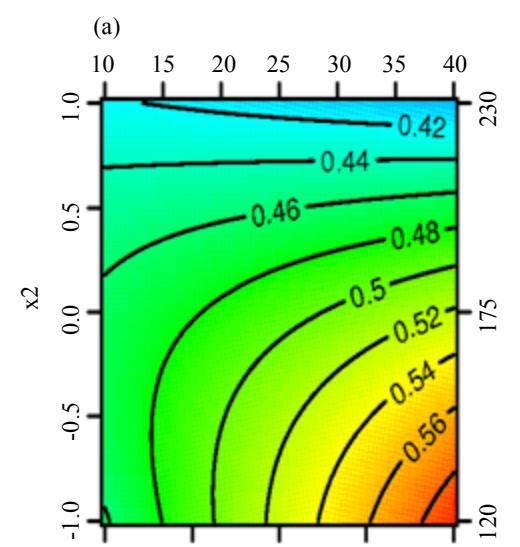

(d)

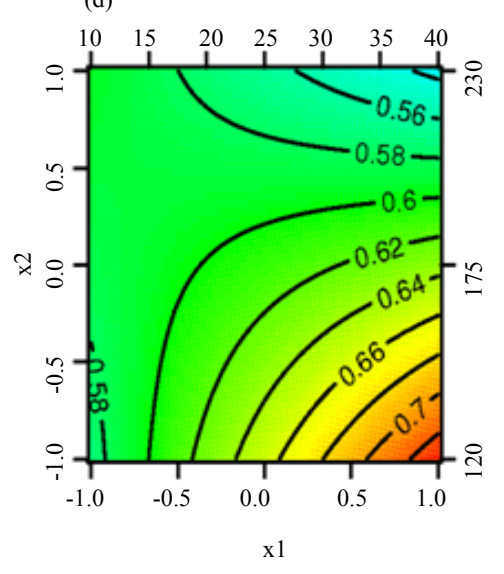

(b) Fee concentrations $(\%, w / w)$

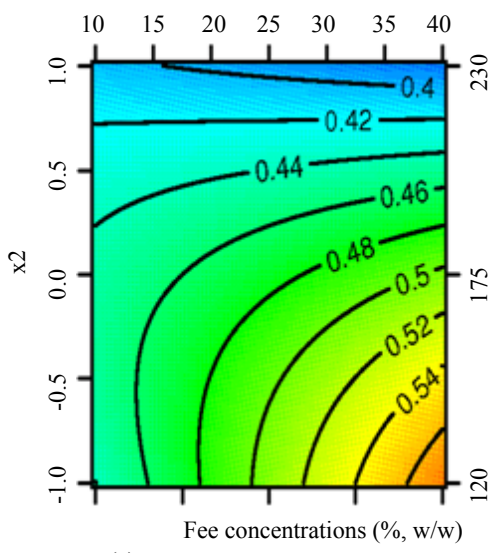

(e)

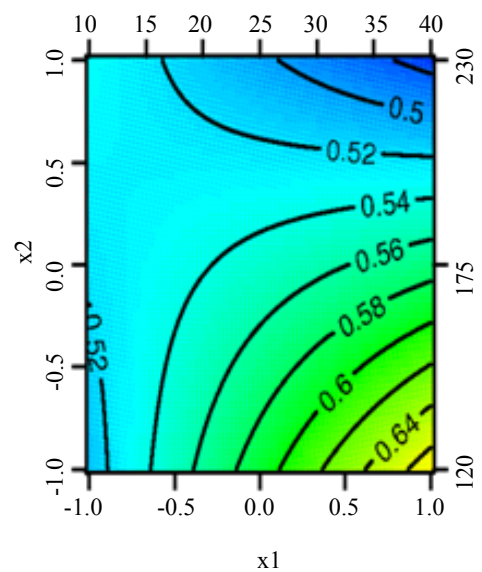

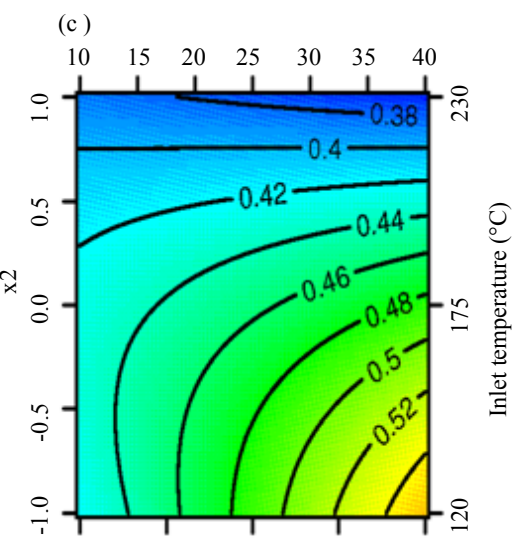

(f)

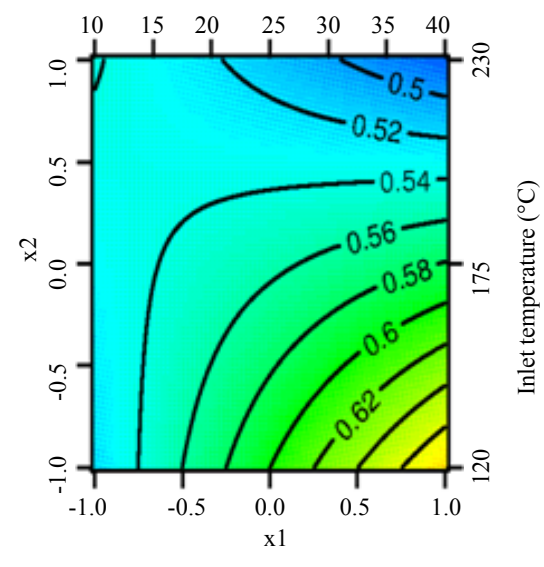

Fig. 3(a-f): Contour plot of the response-surface model fitted to bulk density (a) and tapped density (b). Inlet air temperature of (a) 120 , (b) 175 and (c) $230^{\circ} \mathrm{C} . \mathrm{x}_{1}$ : feed concentration $(-1: 10 \%, 0: 25 \%,+1: 40 \%), \mathrm{x}_{2}$ : inlet air temperature $\left(-1: 120^{\circ} \mathrm{C}, 0: 175^{\circ} \mathrm{C},+1: 230^{\circ} \mathrm{C}\right)$

time for structures to deform, shrink and collapse (Pourfarzad et al., 2015). To a lesser extent, the particles size increased with the feed concentration. As the feed concentration decreased, less dry substance was present in the droplets after atomization, leading to smaller particles after drying.

Bulk and tapped density: The selected models for the bulk and tapped density are presented in Table 4 . They have similar trends and included linear terms corresponding to the feed concentration, inlet air temperature and feed temperature, a quadratic term corresponding to the inlet air temperature (for bulk density) or feed temperature (for tapped density) and the interaction between feed concentration and inlet air temperature. They presented a residual error of 0.0264 (21 df) and 0.0363 (21df) and an adjusted- $\mathrm{R}^{2}$ of 0.820 and 0.703 for bulk and tapped density, respectively. The models did not show any significant, lack of fit $\left(\mathrm{F}_{3,18}=0.467, \mathrm{p}=0.709\right.$ for bulk density $\mathrm{F}_{3,18}=0.738$, p-valeu $\mathrm{r}=0.543$ for tapped density). Bulk density increased with the inlet air temperature in a quadratic manner, meaning that the density increase between $\mathrm{T}_{\mathrm{in}}=120$ and 175 was less pronounced than between $\mathrm{T}_{\text {in }}=175$ et $230^{\circ} \mathrm{C}$. This is probably due to the blow-out of inulin particles at $\mathrm{T}_{\text {in }}=230^{\circ} \mathrm{C}$ as confirmed by electronic microscopy analysis (arrows in Fig. 2). After exceeding a given temperature, the gas pressure inside the particles was so, high that it caused particle fracture (destruction). Bulk density of the material composed of crumbled particles was high because they did not form a close porous structure filled with air as observed elsewhere on maltodextrin (Le et al., 2019).

Figures $3 \mathrm{a}$ and $\mathrm{b}$ reveal in low feed temperature, a significant effect of the feed concentration on both bulk and tapped density. However, at higher feed temperature, feed concentration had almost no impact on the densities. Such a difference in the curve shape is due to the existing interaction between inlet air temperature and feed concentration (Table 4). 
Table 4: Response-surface coefficients of the final fitted model for bulk density and tapped density

\begin{tabular}{lrrrc}
\hline Parameters & Coefficient & SE & t-test & p-values \\
\hline Bulk density & & & & \\
Intercept & 0.474444 & 0.008785 & 54.006 & $<0.001^{* * *}$ \\
$\mathrm{X}_{1}$ & 0.028889 & 0.006212 & 4.650 & $<0.001^{* * *}$ \\
$\mathrm{X}_{2}$ & -0.056111 & 0.006212 & -9.033 & $<0.001^{* * *}$ \\
$\mathrm{X}_{3}$ & -0.018444 & 0.007858 & -2.347 & $0.029^{*}$ \\
$\mathrm{X}_{22}$ & -0.023889 & 0.010760 & -2.220 & $0.038^{*}$ \\
$\mathrm{X}_{1}: \mathrm{X}_{2}$ & -0.038000 & 0.009624 & -3.949 & $0.001^{* * *}$ \\
Tapped density & & & & \\
Intercept & 0.547037 & 0.013059 & 41.891 & $<0.001^{* * *}$ \\
$\mathrm{X}_{1}$ & 0.025000 & 0.008549 & 2.924 & $0.008^{* *}$ \\
$\mathrm{X}_{2}$ & -0.043889 & 0.008549 & -5.134 & $<0.001^{* * *}$ \\
$\mathrm{X}_{3}$ & -0.026667 & 0.011309 & -2.358 & $0.028^{*}$ \\
$\mathrm{X}_{32}$ & 0.035556 & 0.016555 & 2.148 & $0.044^{*}$ \\
$\mathrm{X}_{1}: \mathrm{X}_{2}$ & -0.054444 & 0.014807 & -3.677 & $0.001^{* *}$ \\
\hline
\end{tabular}

Table 5: Response-surface coefficients of the final fitted model for glass transition temperature

\begin{tabular}{lcccc}
\hline Parameters & Coefficient & SE & t-test & p-values \\
\hline (Intercept) & 93.789 & 2.900 & 32.345 & $<0.001^{* * *}$ \\
$\mathrm{x}_{1}$ & 7.544 & 2.050 & 3.679 & $0.001^{* *}$ \\
$\mathrm{x}_{2}$ & 13.709 & 2.050 & 6.686 & $<0.001^{* * *}$ \\
$\mathrm{x}_{22}$ & -7.906 & 3.551 & -2.226 & $0.036^{*}$ \\
\hline
\end{tabular}

Table 6: Response-surface coefficients of the final fitted model for glass transition temperature corrected for the moisture content which depended on the inlet air temperature

\begin{tabular}{lccrc}
\hline Parameters & Coefficient & SE & t-test & p-values \\
\hline Intercept & 112.8955 & 2.5909 & 43.57 & $<0.001^{* * *}$ \\
${ }^{a}$ Water- $\mathrm{T}_{\mathrm{g}}$ & -9.1274 & 0.8565 & -10.66 & $<0.001^{* * *}$ \\
$\mathrm{x}_{1}$ & 4.1008 & 1.5247 & 2.69 & $0.013^{*}$ \\
\hline${ }^{\mathrm{a}}$ Moisture content associated to the glass transition temperature
\end{tabular}

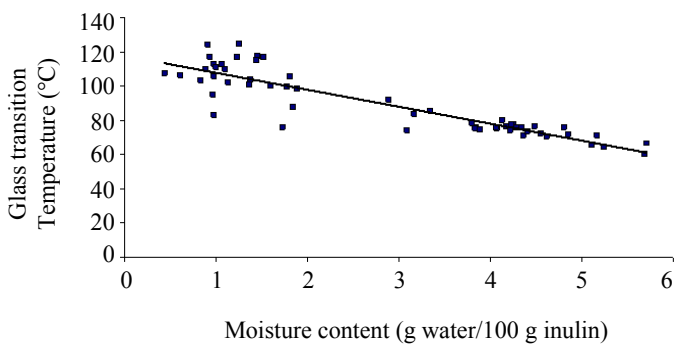

Fig. 4: Glass transition temperature-moisture content relationship of inulin, illustrating the plasticizing effect of water on the glass transition temperature

Glass transition temperature: The selected model (Table 5) only had linear terms corresponding to the feed concentration and the inlet air temperature and a quadratic term corresponding to the inlet air temperature. It presented a residual error of 8.6988 ( $23 \mathrm{df})$ and an adjusted- $\mathrm{R}^{2}$ of 0.698 . This model did not show any significant lack of fit $\left(\mathrm{F}_{5,18}=0.700, \mathrm{p}\right.$-value 0.631 ).

By analyzing Fig. 1c and regression coefficients of the model (Table 5), we observed that feed concentration and inlet air temperature both influenced the glass transition Temperature $\left(T_{g}\right)$, independently from one another; inlet air temperature having a higher impact on $\mathrm{T}_{\mathrm{g}}$ than feed concentration.
However, inlet air temperature had an effect on the glass transition temperature only because it directly influenced the moisture content of the powder. Indeed, it is well known that water has an impact on glass transition temperature, phenomenon called plasticization (Nedyalkov et al., 2008; Bchir et al., 2012). The higher a powder's moisture content, the lower its $\mathrm{T}_{\mathrm{g}}$ will be. Figure 4 illustrates raw data of $\mathrm{T}_{\mathrm{g}}$ and the associated moisture content. Such a $\mathrm{T}_{\mathrm{g}}$ moisture content relationship is of crucial importance to evaluate the stability of the powder as it is well established that as soon as the storage or process temperature drops below $\mathrm{T}_{\mathrm{g}}$, sticking (e.g. on the wall of the spray-drier) or caking (e.g., during storage) occurs (Romano et al., 2018). Thus, a new model for the glass transition temperature was established by correcting the moisture content which resulted of the inlet air temperature (Table 6). The selected model was reduced to a unique term (feed concentration), so no contour graph can be drawn. It presented a residual error of 6.322 ( $24 \mathrm{df}$ ) and an adjusted- $\mathrm{R}^{2}$ of 0.8407 . This model did not show any significant lack of fit $\left(\mathrm{F}_{7,17}=0.710, \mathrm{p}\right.$-value $=$ $0.6647)$. We observed that by removing the water impact on the glass transition temperature, the feed concentration was the main factor affecting $\mathrm{T}_{\mathrm{g}}$. As the feed concentration increased, the glass transition temperature increased (by around $4{ }^{\circ} \mathrm{C}$ per $15 \%$, w/w). So, Tg was modified by the feed concentration changes prior to the spray-drying. This was probably due to a modification of the molecular packing of inulin in the solution (as no crystallization occurred) which had an impact on the devitrification process when the powder was heated. This assumption is based on the research by Surana et al. (2004) which pointed out that the method of preparation of a solid trehalose amorphous strongly influenced its glass transition temperature.

\section{CONCLUSION}

Response-surface design allowed to investigate the impact of the feed temperature and concentration and inlet air temperature of the pilot spray-drier to the bulk and tapped density, particles size, moisture content and the glass transition temperature of the resulting amorphous inulin powders. The adjusted models permitted to point out and to predict the impact and the interactions between these pertinent spray-drier parameters and the physico-chemical properties of the powder. As a general trend, the air temperature presented the strongest influence on the different properties of the powder, followed by the concentration in inulin of thse feed. The feed temperature seemed to only play a marginal role in this process. Particles size depended on the feed concentration and the inlet air Temperature $\left(T_{\text {in }}\right)$. Between $\mathrm{T}_{\text {in }}=175$ and $230^{\circ} \mathrm{C}$, a blow-out of the particles occurred and was observed by electronic microscopy. It led to a decrease of the bulk and tapped density of the powder. 
Moisture content was greatly affected by the inlet air temperature and the feed concentration to a lesser extent and had a direct impact on glass transition temperature of inulin as a plasticizing agent.

\section{Ethical statemnts:}

Conflict of interest: The researchesr declare that they do not have any conflict of interest.

Ethical review: This study does not involve any animal testing.

Informed consent: Written informed consent was obtained from all study participants.

\section{ACKNOWLEDGEMENT}

The reserearchers are grateful to Jean-Christophe Lambrechts from the CERTECH (Seneffe, Belgium) for the electron microscopy micrographs.

Financial funding: This study has no sources of financial funding and support.

\section{REFERENCES}

Ahmed, I., M.B.K. Niazi, Z. Jahan and S.R. Naqvi, 2018. Effect of drying parameters on the physical, morphological and thermal properties of spray-dried inulin. J. Polym. Eng., 38: 775-783.

Ahmed, J., L. Thomas and R. Khashawi, 2019. Dielectric, thermal and rheological properties of inulin/water binary solutions in the selected concentration. J. Food Process Eng., Vol. 42, No. 2.

Alamilla-Beltran, L., J.J. Chanona-Perez, A.R. Jimenez-Aparicio and G.F. Gutierrez-Lopez, 2005. Description of morphological changes of particles along spray drying. J. Food Eng., 67: 179-184.

Bchir, B., N. Sadin, S.N. Ronkart and C. Blecker, 2019. Effect of powder properties on the physicochemical and rheological characteristics of gelation inulin-water systems. Colloid Polymer Sci., 297: 849-860.

Bchir, B., S. Besbes, R. Karoui, H. Attia, M. Paquot and C. Blecker, 2012. Effect of air-drying conditions on physico-chemical properties of osmotically pre-treated pomegranate seeds. Food Bioprocess Technol., 5: 1840-1852.

Birchal, V.S., M.L. Passos, G.R. Wildhagen and A.S. Mujumdar, 2005. Effect of spray-dryer operating variables on the whole milk powder quality. Drying Technol., 23: 611-636.

Chen, G., C. Li, S. Wang, X. Mei, H. Zhang and J. Kan, 2019. Characterization of physicochemical properties and antioxidant activity of polysaccharides from shoot residues of bamboo (Chimonobambusa quadrangularis): Effect of drying procedures. Food Chem., 292: 281-293.
Hancock, B.C. and M. Parks, 2000. What is the true solubility advantage for amorphous pharmaceuticals?. Pharm. Res., 17: 397-404.

Haraguchi, K., 2015. Difructose dianhydride III producing inulin fructotransferase from Microbacterium sp. S48-1. Food Biotechnol., 29: 156-165.

Jirayucharoensak, R., K. Khuenpet, W. Jittanit and S. Sirisansaneeyakul, 2019. Physical and chemical properties of powder produced from spray drying of inulin component extracted from Jerusalem artichoke tuber powder. Drying Technol., 37: 1215-1227.

Le, M.Q., R. Carpentier, I. Lantier, C. Ducournau, F. Fasquelle, I. Dimier-Poisson and D. Betbeder, 2019. Protein delivery by porous cationic maltodextrin-based nanoparticles into nasal mucosal cells: Comparison with cationic or anionic nanoparticles. Int. J. Pharmaceutics X, Vol. 1,

Nath, S. and G.R. Satpathy, 1998. A systematic approach for investigation of spray drying processes. Drying Technol., 16: 1173-1193.

Nedyalkov, M., L. Alexandrova, D. Platikanov, B. Levecke and T.F. Tadros, 2018. Wetting properties of aqueous solutions of hydrophobically modified inulin polymeric surfactant. Colloid Polym. Sci., 286: 713-719.

Nijdam, J.J. and T.A.G. Langrish, 2005. An investigation of milk powders produced by a laboratory-scale spray dryer. Drying Technol., 23: 1043-1056.

Pinto, S.S., B.D. Cavalcante, S. Verruck, L.F. Alves, E.S. Prudencio and R.D. Amboni, 2017. Effect of the incorporation of Bifidobacterium BB-12 microencapsulated with sweet whey and inulin on the properties of Greek-style yogurt. J. Food Sci. Technol., 54: 2804-2813.

Pourfarzad, A., M.H. Najafi, M.H. Khodaparast and M.H. Khayyat, 2015. Physicochemical properties of serish root (Eremurus spectabilis) fructan as affected by drying methods. Qual. Assur. Safety Crops Foods, 7: 687-696.

Romano, N., P. Mobili, M.E. Zuniga-Hansen and A. Gomez-Zavaglia, 2018. Physico-chemical and structural properties of crystalline inulin explain the stability of Lactobacillus plantarum during spray-drying and storage. Food Res. Int., 113: 167-174.

Ronkart, S., C. Blecker, C. Fougnies, J.C.V. Herck, J. Wouters and M. Paquot, 2006. Determination of physical changes of inulin related to sorption isotherms: An X-ray diffraction, modulated differential scanning calorimetry and environmental scanning electron microscopy study. Carbohydr. Polym., 63: 210-217. 
Ronkart, S.N., M. Paquotb, C. Fougnies, C. Deroanne and C.S. Blecker, 2009. Effect of water uptake on amorphous inulin properties. Food Hydrocolloids, 23: 922-927.

Ronkart, S.N., M. Paquot, C.S. Blecker, C. Fougnies and L. Doran et al., 2009a. Impact of the crystallinity on the physical properties of inulin during water sorption. Food Biophys., 4: 49-58.

Samborska, K., J. Suszek, E. Hac-Szymanczuk, A. Matwijczuk and B. Gladyszewska et al., 2018. Characterization of membrane processed honey and the effect of ultrafiltration with diafiltration on subsequent spray drying. J. Food Process Eng., Vol. 41, No. 6.

Surana, R., A. Pyne and R. Suryanarayanan, 2004. Effect of preparation method on physical properties of amorphous trehalose. Pharm. Res., 21: 1167-1176.
Vega, O., L.M. Carvajal, F. R o driguez, M.C. Marin, C. Ramirez, R. Simpson and M. Valdenegro, 2018. Effect of thermal pretreatments and cooking characteristics on physicochemical, rheological and sensorial properties of food products based on cassava (Manihot esculenta Crantz). J. Food Process Eng., Vol. 41, No. 1

Verdurmen, R.E.M., P. Menn, J. Ritzert, S. Blei and G.C.S. Nhumaio et al., 2004. Simulation of agglomeration in spray drying installations: The EDECAD project. Drying Technol., 22: 1403-1461.

Zhang, L., J. Qiu, X. Cao, X. Zeng, X. Tang, Y. Sun and L. Lin, 2019. Drying methods, carrier materials and length of storage affect the quality of xylooligosaccharides. Food Hydrocolloids, 94: 439-450. 